\title{
The New Early Years Professional in England
}

\author{
Eunice Lumsden \\ The University of Northampton, United Kingdom
}

\begin{abstract}
In March 2006 the former British Labour Government (1997-2010) introduced a new professional, the Early Years Professional with status (EYPS). It has been presented as the 'Gold Standard' in early years and every full time day-care setting should have an Early Years Professional by 2015. The last five years have seen intense activity to develop frameworks to support the EYPS 'production line' and there are now five training routes. This paper aims to disseminate some of the challenges of establishing a new professional imposed by central government rather than grown organically. It will specifically report on research undertaken with candidates on the 'pilot phase' of EYPS which forms one strand of ongoing doctorial research into the development of a new professional identity. A mixed methods methodology, using questionnaires and interviews has been employed to ascertain the views of respondents after the assessment and a year later. It concludes that investment in the early years by the UK government is welcomed but the actual introduction of EYPS has had a mixed response, especially because of the initial alignment with teaching. However, data gathered from this distinct group provides insight into emerging professional differences, the assessment process and the importance of continual professional development.
\end{abstract}

\section{Introduction}

Traditionally professions in England have developed along a separatist rather than an integrated model of service delivery. Each profession has their own 'professional identity' which shapes and impacts on the services provided. This separatist nature of professional development is also reflected in the way services for children and families have developed. Despite historical perspectives highlighting the importance of services being developed around the child, health, education and social care professions have developed separately [1].
Regardless of this separatist development the need for multi-professional collaboration across health, social care and educational boundaries has been integral to British social policy, though child death enquiries continue to highlight the failure of professionals working together. The Every Child Matters agenda, which is currently dictating the development of services for children and their families in England, clearly recognises the need to improve all aspects of multi-professional working. Indeed, the development of a new workforce strategy, with professionals sharing core competences is one of the challenges facing all levels of training.

One of the responses to this direction of travel has been the introduction of the Early Years Professional (EYP). This is an unprecedented development for those who work with children from birth to five, a new multi-disciplinary professional role introduced at graduate level, rather than grown organically. Responsibility for the Early Years Professional Status (EYPS) training pathways has been assigned to the Children's Workforce Development Council (CWDC). This new professional in England is being presented as the 'Gold Standard' in early years and every full time day-care setting should have an EYP by 2015 .

There are five routes to EYPS, the Validation Pathway which takes four months part time and is aimed at those holding a relevant degree with practice experience. The Short Pathway which is six months part time and also aimed at those with a relevant degree but in need of additional training to develop their knowledge and skill base. The Long Pathway provides a fifteen month part time route aimed at those who already have a foundation degree in early years or a relevant area and need to obtain and ordinary degree before completing EYPS. The fourth route, the Full Pathway offers an opportunity for those with a none relevant degree to undertake intensive training over a year and is akin to the post graduate teaching training course. The latest Undergraduate Pathway introduced in September 2009 offers a new professional pathway opportunity for those undertaking the Early Childhood Studies degree, though this route currently is only being delivered by a few universities [2]. 
The overly prescribed, formulaic, labour intensive and subsequently expensive assessment process was devised by consultants, with candidates having to evidence the EYPS standards. Candidates are allocated a mentor and undertake four days preparation and a half day assessment of need, where a range of observed activities are undertaken and formative feedback to support their final setting visit is provided. This visit comprises of an analysis of written tasks, a setting tour and interviews with witnesses and the candidate. Secrecy rather than openness prevails and a declaration has to be signed that candidates will not discuss the content of the needs assessment or the setting visit with others. Furthermore the assessor cannot discuss or give any indication of the outcome of the setting visit to the candidate. There is then a wait of several months before the candidate receives their result. During this time a lengthy internal and national moderation process takes place.

Not surprisingly the development has produced considerable debate in the early years community and beyond about the EYP role, salary levels, positioning with other professionals in early years especially the early years teacher and the assessment process. Hence the last five years has seen intense activity developing frameworks to support the EYPS 'production line' and they are now beginning to lead practice in the early years.

The speed of the expansion has inevitably made it difficult to undertake and disseminate evidenced based research to support the ongoing development of the role. This paper aims to address this situation by reporting on the first phase of a longitudinal research project which explores the concept of professional identity through a critique of the concept, implementation and impact of EYPS as a new professional model. It is particularly concerned with the research that took place between 2007 and 2008 with candidates in the 'pilot phase' of the implementation of the EYPS in the central England. The 'pilot' aimed to test out the assessment process for the status that was delivered by an uneasy mix of eleven academic and private providers. Questionnaires were undertaken at the end of the EYPS assessment and one year later. Interviews were also completed one year after the award.

\section{Literature Review}

\subsection{Background}

The election of the New Labour Government in 1997 saw the traditional distinction between education and care in the early years being addressed with a raft of policy initiatives [3]. Indeed, there are not many times when government initiatives are as welcomed as those aimed at raising quality in the early years [4]. The former Labour Government (1997-2010) mantra as they introduced the National Childcare Strategy was 'Good quality, affordable childcare for children aged 0-14 in every neighborhood,' [5]. Underpinning this change was the formal acceptance of what earlier early years pioneers had argued for, that early intervention would improve outcomes for the whole of society.

The early years reform agenda was part of wider changes in services that have led to structural changes in the provision of services for children and families, with greater focus being placed on multiprofessional working. These changes were impacted upon by the death of Victoria Climbé in 2001 and the subsequent Laming Inquiry. The recommendations of the inquiry led to a radical reform agenda for children's services and the publication of Every Child Matters Green Paper. This agenda included five outcomes for all children. They are: stay safe, be healthy, enjoy and achieve economic well-being and contribute to society.

The Children Act 2004 provides the legal framework for these outcomes. It underpins the drive to improve services through multi-agency working and an integrated approach to care and education services. Each local authority had to appoint a Director of Children's Services responsible for education and social care. In addition the CWDC was established to overview workforce reform, though the Coalition Government that took office in the UK in May 2010 has since decided to close down this organisation, evidencing the real challenges presented to those implementing policy at a time of political change. However, the former Labour Government had also confirmed their commitment to support care as well as education by launching 'A Ten Year Strategy for Childcare' as part of the prebudget report in 2004 [6].

Alongside developments in England, the international context for integrated Early Childhood Education and Care (ECEC) was also the focus of ongoing work by the Organisation for Economic Cooperation and Development [7]. Meanwhile, evidence from a large scale study, the Effective Provision of Pre-school Education (EPPE) [8] reported that better outcomes for children in ECEC settings were linked to higher levels of staff qualification. These findings supported further the former governments agenda for change and 2006 saw the Childcare Act finally removing the distinction between education and care for children under five years old, paving the way for the new statutory Early Years Foundation Stage covering the birth to five age range.

It also introduced EYPS, which was presented as being broadly equivalent to Qualified Teacher Status (QTS). EYP development is pivotal to raising standards in early years practice, particularly in the private, voluntary and independent sector (PVI). The 
pathways for gaining EYPS are varied and a critique of the concept, implementation and impact of EYPS as a new multi-disciplinary professional model is vital to future policy developments in England and ensuring that the quality of early years provision is enhanced to support better outcomes for children.

\subsection{Being a Profession}

Discussion about what is a profession, issues of professionalisation, professionalism and professional identity are complex, multi-layered and constantly evolving. Whilst it can be argued that a tacit understanding is held by all, because professions are an integral part of society, actually deconstructing 'what is a profession?' is challenging. Indeed constructing a definition continues to be the focus of academic debate about what makes one employment group so different from another that it is afforded greater status, privileges and power [9].

Professions traditionally are seen as having expertise in their specific area with the professionals of the nineteenth century being predominantly male, autonomous, not supervised and unregulated. Contemporary professionals tend to work in organisations, are regulated and should no longer be the domain of men or the upper classes. However access by women still evidences inequalities, both in numbers and pay structures and professions, especially the law is still dominated by those who have had the privileges afforded by private rather than public education [10].

It appears more appropriate to view the professions in the $21^{\text {st }}$ Century as fluid entities that have a range of characteristics, such as qualifications, specific training, registration and knowledge and skills related to their loci of practice. Additionally, professions have an ecological dimension that is impacted on by individual, organisational and state interventions, the latter arguably leading to some professions becoming technical in their approach to professionalisation. Indeed, both the personal and the collective shape understanding of the professions and there are vocational and motivational factors that support individuals in making particular professional pathways choices. Additionally a range of socialisation processes occur to support the individual become a member of their chosen profession, evidence their professionalism and make them distinct from other professions, occupations and lay people.

In relation to the area of professional identity, Dobrow and Higgins [11] review the work of Ibarra $\left(1999^{[}\right)$and Schein (1978) and suggested that professional identity is 'relatively stable and enduring constellation of attributes, beliefs, values, motives and experiences.' This definition implies stability and does not acknowledge individual change, the place of either reflective practice, or the impact of other relationships on the professional. However, in trying to tease out what are the specific ingredients of how professional identity is developed, Adams et al. [12] suggest a commonality of 'attitudes, values, knowledge, beliefs and skills' but the way these are visulaised depends on the individual professional. Forde el al. [13] concurs with this but also identify the importance of individual agency being context dependent.

Professional communication was added to the debate by Faber [14]. His review of the literature identified three common factors emerging about professional writings that contribute to an understanding of professional identity. Firstly, they present work for a specific audience, secondly there is a wider social responsibility and finally processes that protects them as owners of knowledge in their field. This provides an interesting perspective about the owners of knowledge. Traditionally professions have put in place entry procedures and regulations about membership. The development of new professional identities, such as the EYP, challenges this. Integrated professions need to draw on the knowledge areas of other established professions to develop their own distinct loci of practice and a professional identity that is clearly recognised by themselves and others.

The EYP also provides opportunity to critique professional dominance and the consequences of introducing a professional group that reflects an integrated rather that separatist model of professional development. Furthermore, the present roles of the EYP as leading and supporting others in relation to the Early Years Foundation Stage are clearly laid down by the government but there is no monitoring of standards through affiliation to a specific professional body. Whilst this is one area that currently divides the EYP from other professions, it is important to recognise that registration procedures have evolved over time when increased regulation was required and the need for accountability acknowledged.

The new professional in early years has also been given 'Status' which implies it can be removed as evidenced in other professions. However the systems for ensuring regulation of the EYP have still to be established. If they are to take their place alongside the growing number of other professions working with children and families then arguably they need to mirror the regulatory requirements that these professions are subject to. This includes the importance of continual professional development (CPD) and whilst the government has not yet placed this requirement on the EYP it has made provision for a support system which includes local support groups. 


\subsection{Multi-professional Working}

One of the perceived strengths of the EYP is their potential to work with other professionals. Indeed, the importance of multi-professional working is widely recognised and the last thirty years has seen a steady growth of policy initiatives, internationally, nationally and locally. These underpin the current policy drive for more effective integrated services and multi professional working and whilst there is a growing interest in research and the growth in literature documenting the challenges and benefits of multi-professional practice to meet the diverse health and social care needs of the community more effectively, education has only recently become more actively engaged in this area [15]. However, despite the policy initiatives and research [16] evidencing the importance of multi-professional working, legislation and policy in England has failed to ensure that multi-professional collaboration is working effectively in meeting the needs of children and their families. The death of Victoria Climbé in 2001 highlighted massive system failure and the resulting policy document Every Child Matters: Change for Children is underpinning a plethora of policy initiatives for children, young people and families, though the death of Baby Peter in 2008, evidenced that shifting the way agencies work takes time and policy direction alone is not enough. If outcomes for children and their families are going to be improved public and private agencies and those working in them need to give more than 'lip service' to an integrated agenda.

Training has a vital role to play here and integral to the policy direction is a highly trained workforce, of which the EYP is part [17]. This new professional should have education, health and social care central to their practice, providing them with a holistic understanding of the child. However achieving this balance in the standards for the EYP proved challenging. The draft standards produced by CWDC in 2006 failed to capture the essence of a generic worker, with a bias towards education [18].

\section{Methods}

This particular strand of the research is concerned with the perceptions of pilot group about the inception of this new professional and their views one year after achieving EYPS. Mixed methods were employed with questionnaires being conducted at the end of the assessment process and a year later. Interviews were also undertaken at this point to gather more in-depth data about how EYPS was being embedded, or not, in the early years sector. The questionnaires included scale and open questions aimed at gathering baseline data from the pilot group to inform further strands of the wider research study. Furthermore, given the speed of the EYP development and the lack of formal evaluation, this strand anticipated capturing data that provided a lens into the inception of an imposed profession that may have some use to the research community. Therefore questions focused on gathering data about how participants viewed the new professional role, pay levels and status, the relationship with teaching and the potential for the role to improve outcomes for children and families. The interviews aimed to provide insight into how EYPS was evolving in practice and deeper understanding of individual perceptions of how being an EYP was influencing their work and the early years community.

\subsection{Sample}

Sixty-two candidates took part in the pilot phase of the EYPS with fifty-four successfully completing it. Thirty responded to the questionnaires at the end of the assessment process, five a year later and five EYPs took part in interviews. They also had some unique background characteristics that are important to note here because of the anticipated roles they would play in the development of EYPS. These included piloting the processes and producing a group that could become mentors and assessors for future candidates. Therefore the majority of respondents were already in senior positions, indeed, eighty-seven percent worked in leadership, managerial and early years advisory roles and ninetythree percent stated that their role involved them in advising the practice of others. Later cohorts undertaking EYP were more in line with the policy direction of the former Labour Government that aimed at a graduate led early years workforce. It is also important to note that the pilot group had professional roles that inevitable meant they already had a well developed sense of their own professional identity. This was particularly evident in the seventy percent of respondents to the first questionnaire who were already qualified teachers.

Other interesting information about the sample includes that they all classified themselves as 'White British' and female. Ninety one percent of the respondents to the first questionnaire were aged thirty to fifty nine. Many of them had responsibilities that related to the wider policy issues of multi-professional working, with seventy percent indicating a direct role in this area. Additionally, seventy seven percent had lead roles in their settings for safeguarding children.

A year after receiving the status only five EYPs responded to the second questionnaire despite several reminders. It was suggested by EYPs that the lack of response was not an indication of their views about EYP rather the nature of their work meant that participation in research, though they 
recognised the value, tended to be pushed to the bottom of their 'to do' list.

Interviews were also conducted a year after the award of EYPS and five EYPs, who were different to the questionnaire response and identified from the first questionnaires took part. Four of these were in leadership and advisory roles and the fifth was a childminder. Three were also qualified teachers and they reflected the diverse range of settings where EYPs are employed. One worked in a children's centre, two in the PVI sector, one for a local authority and the fifth in her own home. They also evidenced the lack of uniformity in role titles being used; theirs included Head of Curriculum, Nursery Manager, Early Years Advisor and Children Centre Teacher.

\section{Data Analysis}

The research sample reflected the gendered nature of the early years workforce and the lack of ethnic diversity, all participants were female and of White British origin. Additionally the respondents mirrored and the range of role titles being used in the sector and interestingly, despite achieving EYPS, none of the questionnaire respondents or those who participated in the interviews were actually using the title EYP. Professions are usually recognised and their roles understood through their professional title. For example, the terms doctor, teacher, nurse, social worker and solicitor provides others with a picture of what they do, where they may work and what their training may have required. Arguably if the title EYP is not used it will be extremely difficult to establish this new profession and for others to develop an understanding about who they are, their role and the level at which they are qualified.

The pilot was particularly aimed at testing out the processes and establishing a group of EYPs to underpin future developments. This was reflected in some of the responses received to the question about why they had participated in the pilot. For instance, early years advisors indicated that they completed the status in order to effectively support others in the sector accessing EYP and to contribute to the development of the new professional role. For others however who owned or managed their own nurseries, participation was about protecting their own businesses and meeting the target of one EYP in settings. The cost implications of this development was evident in some of the responses, as one candidate stated she participated “...to protect my own nursery, as I could not afford to employ an EYP."

One of the interesting findings from this particular group was the lack of post graduate qualifications. Whilst it is important not to underestimate the valuable role of 'practice wisdom' the majority of the pilot group held lead and advisory positions however only six of the respondents had accessed a post graduate qualification. Three of these had undertaken a post graduate teaching qualification and the three had completed a master's degree. Thus for some of the respondents the opportunity to complete the status had supported their own CPD. Seventy three percent indicated that it had encouraged reflection on their practice and as one respondent stated "It was a good experience to evaluate my own position, strengths and weaknesses." Furthermore, twenty-seven percent indicated that completing EYPS had motivated them to pursue further qualifications.

In relation to the second questionnaire, whilst it is not possible to generalise from such a small response rate it is interesting to note that despite being in managerial and advisory roles only two had a salary above $£ 15,000$. They all valued being an EYP and saw it has developing a distinct professional role in the early years and that EYPS had made them part of a distinct group. All stated that they believed this new professional has distinct knowledge and understanding and reflecting on practice was an integral part of the role. Thus they provided some hint that EYP potentially displayed some of the ingredients that comprise a profession. However, only three believed their colleagues valued the qualification and none of them believed that parents/carers had heard of EYPS, factors which arguably counteract embedding a new profession role.

\subsection{The Assessment Process and Continual Professional Development}

All of the respondents to the first questionnaire agreed that the standards to achieve EYP were relevant to the role and that the content was relevant to early years practice. They also all found the health and social care elements of the preparation relevant and seventy seven percent agreed that the process had supported them in reflecting on their practice. However there were mixed messages about the assessment process with eighty three percent of the respondents believing that the preparation session were supportive but only forty percent found the needs assessment useful. All candidates are allocated a professional mentor and sixty three percent of respondents agreed this role was useful. It is also important to note that whilst one of the anecdotal complaints about the assessment process was the amount of paperwork involved only twenty three percent found it too complicated

In relation to the setting visit sixty percent had found it too prescribed, though sixty three percent indicated that it was appropriately rigorous and ninety percent welcomed the use of witnesses. The response to a lack of a professional dialogue in the assessment process arguably stems from a more 
technical and formulaic approach to developing a profession and professionalisation. Seventy three percent of the respondents agreed that this would be a useful dimension to the process.

One of the characteristics of established professions is the importance of CPD. The development of EYP at this stage did not include such a framework however ninety percent believed that EYPS should be aligned with other professions and an accredited CPD framework. This was reinforced through the interviews. For example Respondent Two raised the importance of CPD to improve quality services. She suggested that "EYPs are dedicated to their own learning-it is about being committed to my own training so that we can do the best to the children and families with whom we work." This was echoed by Respondent Five commenting that "ongoing training is very important to me-two course last year."

\subsection{Perceptions of Early Years Professional Status}

The first questionnaire aimed to ascertain what the respondents thought about the introduction of the new status and whether it was a positive step forward. Seventy three percent agreed and five were undecided, however only forty seven percent would complete the course again. One reason given was that the status had variable relevance to their current role in the early years sector. One respondent stated "I think EYPS is difficult for people in an advisory capacity not based in a setting" and another "that is difficult for child minders." Sixty four percent believed it would lead to a more skilled workforce concurring with current policy initiative, though thirteen percent disagreed. There was some concern expressed that experienced workers who did not have the appropriate qualifications or did not want to undertake further study were being overlooked. This concurs with the 'Grandmother Principle' which would formally recognise practitioners with considerable experience and practice wisdom through an appropriately rigorous system for accrediting prior learning as advocated by Hevey et al. [19].

Despite concerns in the sector about the introduction of EYPS as the vehicle for improving the quality and training levels of the sector, the five EYPs interviewed really welcomed the fact that the early years were getting political attention and viewed the professionalisation of the workforce positively. They all indicated that perceptions of EYPS within the sector had started to be viewed positively, though it had had varying degrees of impact on their own individual practice. For example Respondent One, a teacher and EYP stated "It does seem much more positive than I thought it would be." For her, completing EYP raised the status of work birth to three and "colleagues [are] very positive really...it raises the profile of the work they do." It also provided her with the opportunity "to deeply reflect on work," arguably an essential professional characteristic for those working with children and families.

Respondent Two, who worked in an advisory role and had qualified teacher status, found that completing EYPS had enhanced her work by developing her knowledge and skill base, which in turn enabled her to support the workforce more effectively. She reported that completing EYPS had developed her knowledge and understanding and made her look at practice differently. This had impacted on her work with others and she indicated that she had been able to enhance the quality of provision in her area and consequently the experiences of children and families using the early years settings. It could therefore be argued that her situation reinforces the importance of CPD as she was already professionally qualified as a teacher and had considerable practice experience.

Respondent Three who also had a teaching qualification and was employed in a private nursery, stated that having EYPS "has made quite a difference" not only to her role, which became setting wide but also in redefining how the setting allocated responsibility and clearer definition was reached about administrative tasks, roles with children and developing the quality of the services provided by the setting. She also indicated that her setting and colleagues valued her achieving EYPS “...but parents do not know what they [EYP] really means." This reflects one of the challenges faced by the implementation of the EYP role as the CWDC had not publicised the introduction of this new professional to the general public. Whilst marketing in the early years sector had increased she continued to state that "I am constantly having to explain what it is even to people within the early years." This situation is compounded by the lack of use of the term EYP discussed earlier. Arguably, therefore, the lack of ownership by CWDC for appropriate marketing strategies has severed as a barrier to EYP development as a distinct recognisable profession.

Not all those interviewed presented a positive picture of the impact of undertaking EYPS on their practice. For Respondent Four it had not impacted on her work but she had not expected it to. She stated: "I did it because as a company they knew we were going to need an EYP." However she did acknowledge the process of completing EYP had enabled her to reflect on her work and it did affirm her knowledge base.

For the final respondent, a childminder, the process had been personally positive but achieving EYP had not changed her role because her sector did not require graduate qualifications. There are also particular issues for those working as childminders 
that make actually undertaking a degree difficult, including that any studying has to be done outside their working day. The incentive to pursue further training was also impacted upon by her local authority withdrawing funding for chidlminders to attain higher qualifications. A situation that she was critical of stating that they "will not support professional development, yet they 'bander' me around as their childminders with EYPS."

Concern was expressed about the long term stability of the EYPS as a new profession. Respondents were particularly concerned with what would happen if there was a change of government and the longer term financial implications. One respondent stated in their questionnaire: "I feel strongly that the government will not achieve their aims...there is simply not enough money in the sector to attract good level 2 and 3 candidates[secondary school level qualifications] in the numbers required. Investing in the top will not solve the very real problems faced by the day care managers when trying to provide quality experiences for children." Her views here reflect some of the real challenges in introducing a graduate workforce in an occupational area that is traditionally female, has low status, pay scales and poor academic and qualification levels.

\subsection{The Relationship with Teaching}

There were mixed and some emotive feelings expressed about the pay scales and the relationship with teaching, with forty three percent indicating that the EYP should be paid the same as teachers. One respondent argued "It is about time early years practitioners received professional and financial credit for the valuable work they do... which are the most important years to invest in." However another respondent was concerned about the impact the introduction of EYPS stating "I feel strongly that this qualification could divide education...an EYP does not have to show competence with managing a large group of children, they do not have to complete a probationary year and are not equivalent to QTS." Indeed sixty seven percent believed that they would never be seen the same as teachers whereas only ten percent did. Those who did not see it as equal were all qualified teachers as one questionnaire respondent argued: "I know it is meant to be the same sort of level but I mean I spent four years obtaining my B Ed...if their [EYPS candidates] degree isn't childcare related I don't think they have the same sort of experiences as people who have QTS."

Arguably, therefore, the data provided through the questionnaires in this strand of the research raised issues that suggested that the promotion of EYPS being 'broadly equivalent to QTS' by the CWDC was problematic. It appeared that the equivalency was taken literally by some rather that recognising that EYP was new and had a broader remit and should have an inter-disciplinary knowledge base and therefore an holistic understanding of the child.

A year later the interviews provided data that evidenced that a greater understanding of the similarities and differences between the two professional roles in the early years was emerging. These included knowledge and understanding of birth to three, in-depth understanding about child development, working multi-professionally, greater participation in team working, wider partnership with the family and leading and supporting others in developing quality services. As Respondent One stated "Early Years Professionals have a wealth of experience with the under threes, which teachers do not but they have expertise in learning and the curriculum, they complement each other."

In relation to knowledge and understanding the case study interviews indicated that the EYP had a broader knowledge base and covered birth to seven, where as the early years teacher was trained three to seven but could teach beyond seven. Additionally a teacher trained in the primary age group could teach in the early years without training in this area. Furthermore Respondent Three raised the issue that in a school setting it would difficult for a head teacher to employ an EYP as they would only be able to use them in the foundation stage whereas a qualified teacher could be moved to “...work with different age groups."

The breadth of the EYP role was raised by Respondent Five who clearly articulated that the role was more holistic that a teacher and they had a role as a change agent. This breadth of knowledge birth to five led Respondent Three to suggest that all early years teachers should have EYP as well and that her own practice as a teacher had been enhanced through gaining the status.

Further insights about the wider role and different knowledge base was highlighted by Respondent One who cited a visit from a former colleague stating "Interestingly for me an ex colleagues [head teacher] that I hold in the highest esteem visited me at this setting she said to me, some of the things you are doing and talking about I have not even heard about." Therefore a year after completing the status the pilot group were able to provide initial data that supported understanding of the emerging role of the EYP.

\section{Conclusion}

The EYP is an emerging role in England and research into the development is embryonic, though the professionalisation of the early years workforce as a whole and the specific introduction of a graduate role was welcomed by the research respondents. It has been introduced to address the need for enhanced quality in the early years, which is part of a wider strategy to radically improve outcomes for all 
children and recognises the long term benefits to the individual and society as ECEC. This has been fuelled by research evidence, international perspectives, child death inquires and the policy drivers of the Labour Party aimed at social inclusion and the eradication of poverty by 2020 .

It is important to acknowledge that a 'quick fix' to the challenges faced is not possible and the long term impact of the change agenda will take decades to be fully realised, if ever. It will be impacted upon by a range of factors including a shift in practice, a more skilled workforce, greater understanding of different professional roles and increased partnership with children and families. Furthermore the agenda is politically sensitive and will be influenced the political ideology of whichever political party is in power, as the demise of the CWDC evidences.

This research project specifically provides base line data to evaluate the development of the EYP and support a richer understanding of the chronological evolution of a new profession in England imposed by the former Labour Government. The data gathered from questionnaires and interviews has provided the opportunity to gain greater insight in to the early development of the EYP role. The pilot group had distinct characteristics which included considerable experience and higher qualification levels. It was interesting therefore that, despite the pilot being akin to the subsequent Validation Route, some of the respondents reported that the process had positively impacted on their knowledge and skill base. This, in turn, supported their work with others and the quality of provision for children. They also welcomed the opportunity to reflect on their practice which had served to reinforce their knowledge, understanding, skills and confidence in their practice.

If the development of a new imposed profession is considered data was generated that indicated the potential for this role to evolve into a profession in its own right with a distinct knowledge base and role. However this development is very embryonic and impeded at this stage by the lack of marketing by the CWDC which means that those working in early years, other professionals in children's services and those using the services have no or little understanding about EYPS. Furthermore the fact that the title EYP does not appear to have been embraced in job titles negates against embedding this new professional role quickly.

It is clear that the introduction has been problematic and challenging especially because of the initial equivalency between EYPS and early years teaching. This notion of 'equivalency' has reportedly produced considerable debate and maybe created some myths about EYPS including the EYP not being as qualified or experienced as the early years teacher and the EYP being viewed as a cheaper and less qualified option. It is important to note therefore that the majority of those participating in the pilot group had considerable experience in the early years, were in senior positions and had qualified teacher status. Their collective views suggest that it is more appropriate that the two roles are seen as complementary not in competition and both the EYP and the early years teacher are needed. Furthermore, one of the strengths of the introduction of EYPS is arguably that it raises the status of birth to three and the distinct knowledge, understanding and skills needed to work in this age range. This in turn reinforces the importance of the birth to five age range and the importance of early intervention in work with children and families.

To conclude this research supports understanding of the challenges of embedding a new professional role that does not have a strong historical and evolutionary heritage. The respondents provide insights into the initial stages of a new profession and base line data that may support the historical understanding of EYPS as a policy development in the early years. It also provides the opportunity to chart how the characteristics of candidates changes over time, the development of professional attributes, how a new professional identity evolves and the relationship with the early years teacher and other professionals working in children's services. Furthermore it provides a framework to evaluate changing perceptions of the EYP and insight into the assessment process. Finally initial data has been generated that indicates that the professionalisation of the early years workforce has been welcomed and the EYP is beginning to impact on the quality of provision.

\section{References}

[1] Nutbrown, K, P. Clough, and P. Selbie, Early Childhood Education, Sage Publications, London, 2008.

[2] Children's Workforce Development Council, How to Become an Early Years Professional, CWDC, Leeds, 2010. http://www.cwdcouncil.org.uk/eyps/how-to-becomean-eyp (12 $2^{\text {th }}$ February 2010).

[3] Baldock, P., D. Fitzgerald, J. Kay, Understanding Early Years Policy, $2^{\text {nd }}$ ed., Sage Publications Ltd., London, 2009.

[4] Booker, L., 'Changing the Landscape of Early Childhood' in Moyles, J. (ed) Early Years Foundations, Open University Press, Maidenhead, 2007.

[5] Department for Education and Employment, Meeting the Childcare Challenge, DfEE Publications, Sudbury, 1998.

[6] Her Majesty's Treasury, Choice for Parents, The Best Start for Children: A Ten Year Strategy for Childcare, HMSO, London, 2004. 
[7] Organisation for Economic and Cultural Development, Starting Strong: Early Childhood Education Childhood, OECD, Paris, 2001.

[8] Sylva, K., E. Melhuish, P. Sammons, I. SirajBlatchford, B. Taggart, and K. Elliot, The Effective Provision of Pre-School Education Project; Findings from the Pre-School Period, DfES Research Brief No: RBX1503, DfES, London, 2003.

[9] Illich, I. Disabling Professions, in: Illich, I., I. Zola, J. Mcknight, J. Caplan and H. Shaiken, (eds.) Disabling Profession, Marion Boyars Publishers Ltd., London, 1977.

[10] The Panel on Fair Access to the Professions, Unleashing Aspiration: The final Report of the Panel of Fair Access to the Professions, The Cabinet Office, London, 2009.

[11] Dobrow, S. and M. Higgins, Developmental Networks and Professional Identity: A Longitudinal Study, Career Development International, Emerald Publications, London, October, 567-583, 2005. www.emeraldinsight.com/1362-0436.htm (12th February 2010).

[12] Adams, K., S. Hean, P. Sturgis, and J. Clark Macleod, Investigating the factors influencing professional identity of first-year health and social care students, Learning in Health and Social Care, Blackwell Publishing Ltd., Bognor Regis, May 2006.

[13] Forde, C., M. McMahon, D. Mcphee, and F. Patrick, Professional Development, Reflection and Enquiry, Paul Chapman Publishers, London, 2006.

[14] Faber, B., Professional Identities: What is Professional about Professional Communication? Journal of Business and Technical Communication, Sage Publications Limited, London, July, 306-337, 2002.

[15] Carnwell, R. and A. Carson, 'Understanding Partnership and Collaboration' in Carnwell, R. and Buchanan, J. (eds), Effective Practice in Health and Social Care: A Partnership Approach, Open University Press, Berkshire, 2005.

[16] Hannon, P. and L. Fox, 'Why Should we Learn from Sure Start,' in Weinberger, J., C. Pickerson and P. Hannon (eds) Learning from Sure Start: Working with Young Children and their Families, Open University Press, Maidenhead, 2005.

[17] Department of Education and Skills, Children's Workforce Strategy: Building a World-Class Workforce for Children, Young People and Families, Department of Education and Skills Publications, Nottingham, 2006.

[18] Children's Workforce Development Council, Early Years Standards Consultation, CWDC, Leeds, 2006.

[19] Hevey, D., E. Lumsden, and S. Moxon, Early Years Professional Status: Pilot Evaluation and Issues, in O’Brien, S., P. Cassidy, and H. Schonfeld. Vision into Practice: Making Quality a Reality for the Lives of Young Children, CEDEC, Dublin, 2008. 